\title{
Intensified concurrent chemoradiotherapy with 5-fluorouracil and irinotecan as neoadjuvant treatment in patients with locally advanced rectal cancer
}

\author{
G Klautke*,', P Feyerherd ${ }^{2}$, K Ludwig $^{3}$, F Prall ${ }^{4}$, T Foitzik ${ }^{2}$ and R Fietkau' \\ 'Department of Radiotherapy, University Hospital, Südring 75, 18059 Rostock, Germany; ${ }^{2}$ Department of Surgery, University Hospital, Rostock, \\ Germany; ${ }^{3}$ Department of Surgery, Klinikum Südstadt, Rostock, Germany; ${ }^{4}$ Department of Pathology, University Hospital, Rostock, Germany
}

\begin{abstract}
This study aimed to evaluate the feasibility and efficacy of neoadjuvant chemoradiotherapy intensified with irinotecan in patients with locally advanced rectal cancer. Eligible patients had nonmetastatic disease at a locally advanced stage that made R0 resection and sphincter preservation uncertain. They received preoperative radiation over 6 weeks to $45 \mathrm{~Gy}$ and boost of 5.4 Gy and concurrent continuous infusion 5-fluorouracil $250 \mathrm{mg} \mathrm{m}^{-2}$ day $^{-1}$ and weekly irinotecan $40 \mathrm{mg} \mathrm{m}^{-2}$. In all, 37 patients entered the study. T stage at baseline as determined by ultrasound was T2/T3/T4 in 2/19/16 patients; 31 patients had lymph node involvement. The predominant toxicity was diarrhoea (grade 3/4 in 10/2 patients). Haematologic toxicity and surgical complications were moderate. Among 36 patients undergoing surgery, 32 (89\%) had R0 resection and 23 (64\%) sphincter preservation. Pathologic complete response (pCR) was achieved in eight (22\%) of 36 patients, and 10 patients (28\%) had only microscopic residual disease. At 4 years, overall survival was $66 \%$, disease-free survival $73 \%$, local relapse rate $7 \%$, and distant failure rate $24 \%$. Extent of resection and postoperative nodal status were significant predictors of overall and disease-free survival. Intensified neoadjuvant chemoradiotherapy with irinotecan can be safely administered and results in a high $\mathrm{PCR}$ rate.

British Journal of Cancer (2005) 92, 1215 - 1220. doi:I0.1038/sj.bjc.6602492 www.bjcancer.com
\end{abstract}

Published online 22 March 2005

(c) 2005 Cancer Research UK

Keywords: rectal cancer; neoadjuvant chemoradiotherapy

It is of critical prognostic significance in rectal cancer whether or not a resection of the tumour with clear margins (R0) can be achieved (Hermanek and Wittekind, 1994). On the other hand, maintenance of foecal continence is of crucial importance for the patients' quality of life. Even if state-of-the art surgical techniques are used, often both of these aims cannot be accomplished in locally advanced tumours, particularly if they are located in the lower third of the rectum. Several phase II studies of 5-fluorouracil-based preoperative chemoradiotherapy for locally advanced rectal cancer have reported $\mathrm{R} 0$ resection rates of $60-85 \%$ (Chan et al, 1993; Minsky et al, 1993; Keilholz et al, 1995; Videtic et al, 1998; Küchenmeister et al, 2000; Rödel et al, 2000) including pathologic complete response (pCR) rates of 5-20\%. Even in low rectal tumours, sphincter-preserving surgery was possible after preoperative chemoradiotherapy in $27-86 \%$ of the patients (Grann et al, 1997; Hyams et al, 1997; Maghfoor et al, 1997; Küchenmeister et al, 2000). Moreover, randomised trials have shown that neoadjuvant chemoradiotherapy improves local control compared with postoperative chemoradiation in primary resectable tumours (Roh et al, 2001; Sauer et al, 2004). The probability of distant metastasis, however, is not reduced. In addition to the well-

\footnotetext{
*Correspondence: Dr G Klautke;

E-mail: gunther.klautke@med.uni-rostock.de

Revised 22 December 2004; accepted 19 January 2005; published online 22 March 2005
}

established agent 5-fluorouracil, new agents such as irinotecan or oxaliplatin have proven effective in the treatment of metastatic colorectal cancer. Therefore, the present phase II study was aimed to determine the feasibility and local efficacy of an intensified neoadjuvant treatment approach using concurrent radiation and chemotherapy with 5-fluorouracil and irinotecan in patients with locally far advanced rectal cancer.

\section{PATIENTS AND METHODS}

\section{Patient eligibility}

Male and female patients with histologically confirmed adenocarcinoma of the rectum were prospectively enrolled in the study if they presented with nonmetastatic disease at a locally advanced stage that made R0 resection and sphincter preservation uncertain. Other eligibility criteria included measurable disease (at least one bidimensionally measurable tumour lesion), WHO performance status $\leqslant 2$, adequate haematologic, hepatic and renal function, and life expectancy of at least 3 months. Pregnant or lactating women, patients with unresolved bowel obstruction or ileus/subileus, and those with a history of chronic diarrhea were ineligible for study entry. All patients underwent baseline examination and staging within 2-4 weeks prior to the start of chemoradiotherapy, including history and physical examination, complete blood count, 
serum chemistry profile, chest X-ray, rectoscopy or sigmoidoscopy, endoluminal ultrasound, abdominal ultrasound, and computed tomography (CT) of the abdomen and pelvis. Inclusion of approximately 35 patients was planned. The study was approved by the local ethics committee, and written informed consent was obtained from all patients.

\section{Treatment}

Computed tomography-assisted three-dimensional planning of radiation therapy was employed. The patients underwent CT with $5 \mathrm{~mm}$ slices, contrast administration to bladder, rectum and small intestine, and endoscopic clipping (Riepl et al, 2000) of the upper and lower borders of the tumour performed immediately prior to planning. Radiation therapy was given with photons from a linear accelerator with energy $>6 \mathrm{MV}$. The target volume comprised the areas at risk including the presacral space along the posterior bladder or vaginal wall, respectively, and the common iliac lymph nodes until and including the fifth lumbar vertebral body. Radiotherapy was delivered with three or four fields using an isocentric technique with individually collimated field portals. Daily fractions of $1.8 \mathrm{~Gy}$ (isodose $90 \%$ of the maximum dose) were given on 5 days a week over 5 weeks to a total dose of $45 \mathrm{~Gy}$ (isodose $90 \%$, corresponding to $47.5-48 \mathrm{~Gy}$ as calculated according to the International Commission on Radiation Units and Measurements (ICRU) reference point approach). An additional low-volume boost of $5.4 \mathrm{~Gy}$ (5.8 Gy by ICRU reference point approach) was given in three fractions on days 1-3 of week 6 of treatment to the site of the primary tumour after previous contrast radiography of the small intestine.

Radiation was administered with concurrent chemotherapy that consisted of 5-fluorouracil given by continuous infusion via an implantable port system at a daily dose of $250 \mathrm{mg} \mathrm{m}^{-2}$ throughout the entire treatment period (days 1-43). In addition, irinotecan was administered once weekly at $40 \mathrm{mg} \mathrm{m}^{-2}$ by 90 -min infusion immediately prior to the first weekly fraction of radiation. Premedication with atropin $0.25 \mathrm{mg}$ subcutaneously was recommended to prevent irinotecan-associated acute cholinergic syndrome. Irinotecan doses were omitted if leucocyte or platelet nadir values were less than $2000 \mu \mathrm{l}^{-1}$ or $<75000 \mu \mathrm{l}^{-1}$, respectively, or if grade 4 toxicity occurred.

Restaging and surgery using total mesorectal excision was to be performed within 4-6 weeks after completion of chemoradiotherapy. Following surgery, patients usually received adjuvant chemotherapy with 5-FU with or without folinic acid according to the recommendations of the German Cancer Society (DKG).

\section{Data evaluation}

The deadline for data evaluation was December 31, 2003. Statistical analysis including survival analysis according to Kaplan-Meier was performed with the SPSS software package. Survival was calculated from the date of histologic verification of diagnosis to the patient's death or the date of last follow-up. Progression-free survival was calculated from diagnosis to the time of first detection of new lesions or progression of residual lesions. Toxicity was graded according to the National Cancer Institute Common Toxicity Criteria (CTC) modified by Seegenschmiedt (1998).

\section{RESULTS}

\section{Patient characteristics}

From July 1, 1999 to December 31, 2001, a total of 37 patients (10 females, 27 males) aged from $41-77$ years (median, 62 years) were referred from the surgeons with locally advanced rectal cancer without distant metastasis to our department. All these patients, fulfilling the including criteria, without any selection were enrolled
Table I Baseline patient characteristics

\begin{tabular}{|c|c|c|}
\hline \multirow[b]{2}{*}{ Variable } & \multicolumn{2}{|c|}{ Patients $(N=37)$} \\
\hline & No. & $\%$ \\
\hline \multicolumn{3}{|l|}{ Gender } \\
\hline Male & 27 & 73 \\
\hline Female & 10 & 27 \\
\hline \multicolumn{3}{|l|}{ Age (years) } \\
\hline Median & 62 & \\
\hline Range & $41-77$ & \\
\hline \multicolumn{3}{|l|}{ T stage } \\
\hline uT2 & 2 & 5 \\
\hline uT3 & 19 & 51 \\
\hline uT4 & 16 & 43 \\
\hline \multicolumn{3}{|l|}{$N$ stage } \\
\hline uNO & 6 & 16 \\
\hline $\mathrm{uN}+$ & 31 & 84 \\
\hline \multicolumn{3}{|c|}{ Tumour localisation ( $\mathrm{cm}$ from anal verge) } \\
\hline $0-5$ & 22 & 59 \\
\hline $5.5-10$ & 13 & 35 \\
\hline$>10$ & 2 & 5 \\
\hline
\end{tabular}

in the study. The main reason for the referral of this patients was an inquestionable $\mathrm{R} 0$ resection without preoperative treatment, because of great tumour mass in the pelvis - the median longitudinal extension of the tumour based on endorectal ultrasound was $6 \mathrm{~cm}$ (range 3-13) - or the infiltration of other organs. In two cases the main reason was a potentially shincter preservation by tumours located in the lower third of the rectum $(0-3 \mathrm{~cm}$, and $1-3 \mathrm{~cm}$ from the anal verge). The patient characteristics are shown in Table 1 . Most tumours were located in the lower third of the rectum (22 patients); in 13 patients the tumour affected the middle third $(5.5-10 \mathrm{~cm}$ from the anal verge) and in two patients the upper third of the rectum $(>10 \mathrm{~cm}$ from the anal verge).

\section{Feasibility and toxicity}

Six doses of irinotecan were given once weekly as planned in 25 $(68 \%)$ of all 37 patients. One and two doses of irinotecan had to be omitted in nine $(24 \%)$ and three $(8 \%)$ patients, respectively, in three cases because of leukopenia grade 3 and 4 , in three cases because of fever, and in six cases because of diarrhoea grade 3 and 4. Acute cholinergic symptoms including acute diarrhoea were not encountered, and premedication with atropin was not required. Thromboembolic events were also not seen. Haematologic toxicity was moderate. Thrombocytopenia grade 3 occurred in one patient $(2 \%)$, and leukopenia grade 3 and 4 in three $(8 \%)$ and one $(2 \%)$ patient, respectively. Anaemia grade $3 / 4$ was not observed. Haemoglobin fell from a median baseline value of $13.2 \mathrm{~g} \mathrm{dl}^{-1}$ (range 10.1 - 16.7) to a median nadir of $11.6 \mathrm{~g} \mathrm{dl}^{-1}$ (range $9.2-15.2$ ) during treatment and reincreased to $12.2 \mathrm{~g} \mathrm{dl}^{-1}$ (range 9.7-15.8) at completion of chemoradiotherapy. The predominant nonhaematologic toxicity was delayed diarrhoea that reached grade 3 in 10 patients $(27 \%)$ and grade 4 in two patients (5\%). Patients with grade 4 diarrhoea were hospitalised and received parenteral nutrition. One patient developed an extrapontine myelinolysis due to severe electrolyte imbalance 2 weeks after completion of therapy; she received appropriate treatment and recovered without sequelae. Three patients ( $8 \%)$ developed fever that could be easily controlled with usual antibiotics. Oral mucositis was not observed, and also no nausea and vomiting grade 2 and higher, because all 
patients received before each application of irinotecan dexamethasone $8 \mathrm{mg}$ and ondansetron $8 \mathrm{mg}$ in a prophylactic way. Abdominal pain, as one criteria in the definition of the grade of diarrhoea in the CTC, was observed in seven patients. Overall, intensified chemoradiotherapy was very well tolerated. Minor complications included transient bladder dysfunction and urinary retention in two patients that resolved completely without any therapy, however, within 2-3 weeks after surgery as a typical side effect of surgery. There were two anastomotic strictures without any symptoms stumbled on 3 months after primary surgery, which required dilatation prior to ileostomy closure. In addition, anastomotic leakage that was amenable to conservative treatment occurred in two patients, and one perianal wound infection with subsequent secondary healing.

In one patient chemoradiotherapy had to be discontinued after $40 \mathrm{~Gy}$ for signs and symptoms of an acute abdomen. A stenosis of the small intestine was detected in the radiation field in this patient; he underwent surgery during the acute phase, and subsequent reoperation was necessary due to an anastomotic leak.

\section{Resectability and type of surgery}

Of the 37 patients, 36 proceeded to surgery after completion of neoadjuvant chemoradiotherapy. One patient refused surgery because an exploratory biopsy had shown no evidence of residual tumour. An R0 resection was possible in 32 (89\%) of the 36 patients undergoing surgery; the four (11\%) remaining patients had an R1 resection. Sphincter preservation could be achieved in $23(64 \%)$ of 36 patients, while a radical resection of the rectum was required in $13(36 \%)$ patients. Table 2 shows the surgical approach by tumour height. So sphincter-saving surgery was possible in 10 of 22 patients $(45 \%)$ with a tumour less or $5 \mathrm{~cm}$ from the anal verge, and in 21 of 34 patients (61\%) with a tumour less or $10 \mathrm{~cm}$ from the anal verge.

\section{Pathologic response and downstaging}

Histologic examination of the resection specimens demonstrated a pCR of the primary tumour in eight of 36 patients $(22 \%)$. The inclusion of the patient who had only an exploratory biopsy increased the pCR rate to $24 \%$ (nine out of 37). In all, 10 patients (28\%) had only microscopic residual disease (MRD), and 14 patients (39\%) had a tumour regression by more than $50 \%$, resulting in a pathologic partial response rate of $67 \%$. A minor response was achieved in four (11\%) patients. No patient failed to

Table 2 Surgical approach by tumour height

\begin{tabular}{lccc}
\hline & \multicolumn{3}{c}{ Surgical approach (No. of patients) } \\
\cline { 2 - 4 } Tumour height $\mathbf{( c m )}$ & Sphincter-saving & Radical & Total \\
\hline $0-5$ & 10 & 12 & 22 \\
$5.5-10$ & 11 & 1 & 12 \\
$>10$ & 2 & 0 & 2 \\
\hline
\end{tabular}

Table 3 Pathologic downstaging of the primary tumour

\begin{tabular}{lcccccc}
\hline & \multicolumn{6}{c}{ Pathologic T stage at the time of surgery (patients) } \\
\cline { 2 - 7 } $\begin{array}{l}\text { Clinical T stage } \\
\text { at baseline }\end{array}$ & $\mathbf{p T 0}$ & $\mathbf{p T 1}$ & $\mathbf{p T 2}$ & $\mathbf{p T 3}$ & $\mathbf{p T 4}$ & Total \\
\hline CT2 & 1 & 0 & 0 & 1 & 0 & 2 \\
CT3 & 4 & 1 & 7 & 7 & 0 & 19 \\
CT4 & 4 & 0 & 2 & 9 & 1 & 16 \\
Total & 9 & 1 & 9 & 17 & 1 & 37 \\
\hline
\end{tabular}

respond. Tumour downstaging by at least one $\mathrm{T}$ category was achieved in $28(76 \%)$ of all 37 patients (Table 3$)$. The pathologic lymph node status at the time of surgery was pN0 in 25 of 36 patients $(69 \%), \mathrm{pN} 1$ in five patients $(14 \%)$, and $\mathrm{pN} 2$ in six patients (17\%).

\section{Disease control and survival}

At a median follow-up of 40 months (range 28-53), 10 of 37 patients had died, of which eight succumbed to their disease. One patient died after 5 months of pulmonary embolism and another one after 2 years of congestive heart failure. The estimated local relapse rate ( \pm standard deviation) at 4 years was $7 \pm 5 \%$. One patient developed an isolated local recurrence, and another patient had synchronous local recurrence and liver metastasis. The rate of distant metastasis at 4 years was $24 \pm 7 \%$. Among patients with R0 resection, the rate of distant metastasis was $14 \pm 6.3 \%$. The actuarial progression-free and overall survivals at 4 years were $73 \pm 7.6$ and $66 \pm 8.6 \%$, respectively, the disease-specific overall survival at 4 years was $70 \pm 8.7 \%$.

Among postoperative disease variables, the resection (R) and nodal $(\mathrm{N})$ status and the pathohistological response rate were found to be the most important prognostic determinants. Overall survival at 4 years was $81 \pm 7.1 \%$ among patients with an R0 resection compared with $0 \%$ among those who had an $\mathrm{R} 1$ resection $(P=0.013)$. Disease-specific survival rates at 4 years were $84 \pm 6$ and $0 \%$ for the R0 and R1 patient subgroups, respectively $(P=0.0001)$. Patients with no pathologic evidence of lymph node involvement ( $\mathrm{pN} 0)$ after neoadjuvant chemoradiotherapy had a 4 -year progression-free survival of $92 \pm 6.1 \%$ (Figure 1) compared with $80 \pm 17.9 \%$ for patients with pN1 and $0 \%$ for those with pN2 $(P<0.0001)$. Overall survival at 4 years was $80 \%$ among patients with pN0 or pN1 status compared with $33 \%$ among patients with pN2 $(P=0.01)$. The progression-free survival at 4 years for patients with complete responses or only MRD was $88 \pm 8 \%$ (Figure 2) and for patients with only partial response $58 \pm 12 \%$ $(P=0.06)$.

\section{DISCUSSION}

The primary aim of treatment for rectal cancer is to achieve complete resection of the tumour and, in the long term, a high local control and low distant failure rate. An additional aim in low

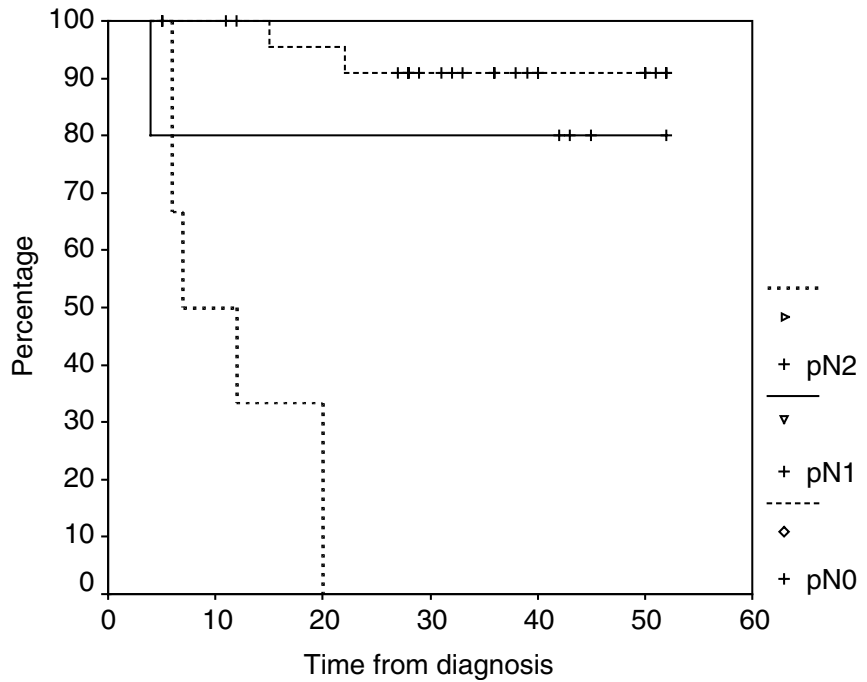

Figure I Progression-free survival by nodal status: $p N 0,25$ patients (4year PFS 92 \pm 6.1\%); pNI, five patients (4-year PFS $80 \pm 17.9 \%$ ); pN2, six patients (4-year PFS 0\%). $P<0.0001$. 


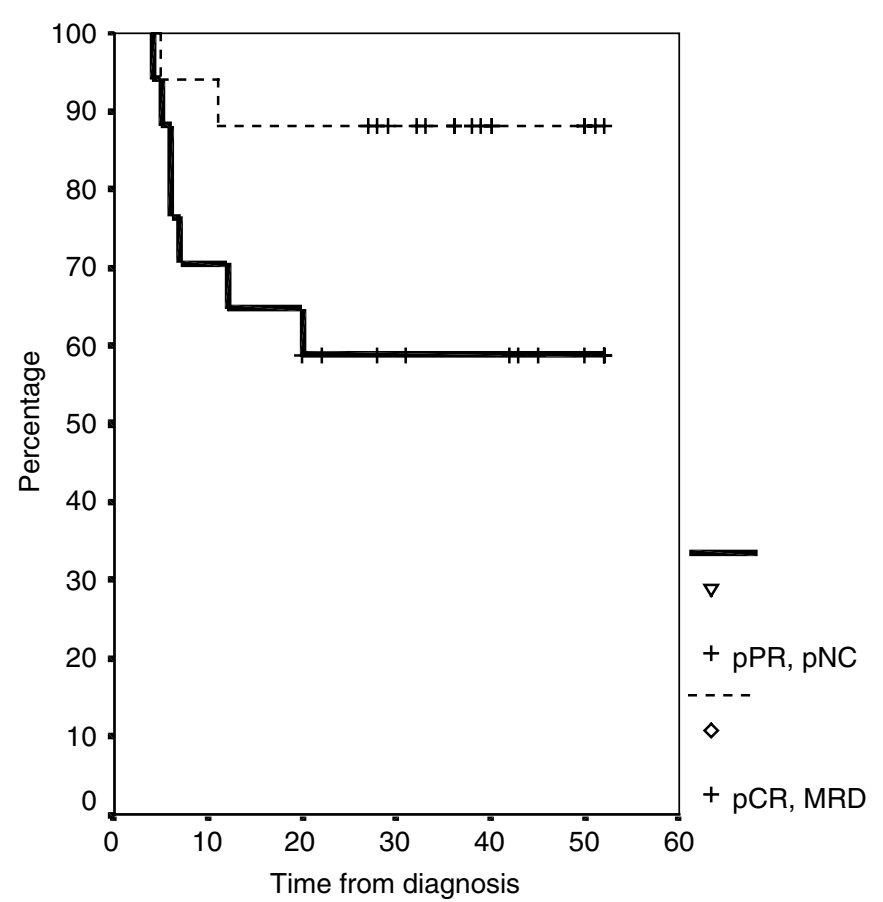

Figure 2 Progression-free survival by response status: pCR, MRD: 18 patients (4-year PFS $88 \pm 8 \%$ ); pPR, pNC 18 patients (4-year PFS $58 \pm 12 \%) ; P=0.06$.

rectal tumours is sphincter preservation. These objectives are difficult to meet in advanced stages of the disease, and treatment outcome often remains unsatisfactory in this setting. To improve the prognosis compared with surgery alone, neoadjuvant 5fluorouracil-based chemoradiotherapy has been introduced, with 5-fluorouracil given as a bolus or continuous infusion, with or without folinic acid. Although these studies reported high rates of $\mathrm{R} 0$ resection, $\mathrm{pCR}$, and sphincter saving, even in low tumours, many patients eventually developed local or, more common, distant recurrences. Intensification of neoadjuvant therapy appears a promising approach to eradicate potential micrometastases more effectively prior to surgery. Since new agents have improved treatment results in the palliative setting, several phase II studies have recently been initiated to examine the usefulness of these agents given concurrently with radiotherapy as neoadjuvant treatment. The most promising of these agents are oxaliplatin and irinotecan. We added irinotecan to 5-fluorouracil in our study for two reasons: Owing to its high activity in advanced colorectal cancer (Douillard et al, 2000; Saltz et al, 2000) irinotecan appears particularly suited for intensified induction therapy; in addition, several studies have documented the radiosensitising properties of irinotecan (Boothmann et al, 1987; Boscia et al, 1993; Omura et al, 1997; Chen et al, 1999) that were observed even under hypoxic conditions (Boscia et al, 1993). As hypoxia may have an adverse effect on the radiosensitivity of cells (Kumar, 2000; Fyles et al, 2000 ), irinotecan may be particularly useful as a constituent of chemoradiotherapy programmes in patients with bulky pelvic tumours and poor blood supply that often contain hypoxic regions.

The $\mathrm{R} 0$ resection rate of $89 \%$ in our study is in the upper range of results reported for neoadjuvant chemoradiotherapy in locally advanced rectal cancer with 5-fluorouracil alone. Moreover, our long-term local control rate of $93 \%$ at 4 years is comparable to the results achieved with concurrent 5-fluorouracil and radiation in the study of the German Rectal Cancer Group (Sauer et al, 2004), even though patients in this study had on average less advanced disease. Sphincter-saving surgery was possible in our study in as many as $10(45 \%)$ out of 22 patients with very low rectal cancers ( $\leqslant 5 \mathrm{~cm}$ from anal verge), most of which would have required total resection if no neoadjuvant treatment had been given. One of these 10 patients developed after 15 months distant metastasis in the liver and a locoregional recurrence, and died after 39 months with normal sphincter function.

The intensified neoadjuvant multi-modality programme with 5fluorouracil, irinotecan, and concurrent radiation that we used in our study shows a higher rate of diarrhoea compared with studies using only 5 -fluorouracil in different ways. So, in schemes with only 5 -fluorouracil, the rate of grade $\frac{3}{4}$ diarrhoea is about $20-25 \%$; adding irinotecan, the rate of grade $\frac{3}{4}$ diarrhea is about $30-40 \%$. In our study the rate of grade $\frac{3}{4}$ diarrhoea was $32 \%$ and this is in keeping with the findings in other studies using this combination (Mitchell et al, 2001; Mehta et al, 2003). Therefore, this intensified neoadjuvant scheme with 5-fluorouracil, irinotecan, and concurrent radiation must include an intensified care and supportive treatment for the patients. Then this scheme is safe and effective. Since both 5-fluorouracil and pelvic radiation cause diarrhoea as an adverse effect, irinotecan cannot be administered at weekly doses of $80-100 \mathrm{mg} \mathrm{m}^{-2}$ that are usually given in combination with 5-fluorouracil and folinic acid without radiation therapy (Douillard et al, 2000; Saltz et al, 2000). We chose an irinotecan dose of $40 \mathrm{mg} \mathrm{m}^{-2}$, while $50 \mathrm{mg} \mathrm{m}^{-2}$ was used in the other published studies, though in combination with a lower daily dose of 5-fluorouracil $\left(225 \mathrm{mg} \mathrm{m}^{-2}\right)$ compared with our regimen $\left(250 \mathrm{mg} \mathrm{m}^{-2}\right)$. The total doses of irinotecan were 200 and $250 \mathrm{mg} \mathrm{m}^{-2}$ in the other studies (Mitchell et al, 2001; Mehta et al, 2003) and $240 \mathrm{mg} \mathrm{m}^{-2}$ in the present trial. Diarrhoea was also a predominant nonhaematologic toxicity seen with other chemoradiation protocols (Table 4). Nevertheless, adding irinotecan to radiation and 5-fluorouracil the rate of diarrhoea is higher, but this acute toxicity is manageable with an intensified care and if needed with supportive treatment.

The effectivity of neoadjuvant therapy of rectal cancer is usually measured by the rate of pathologically confirmed complete responses (pCR). A pCR rate of $8-10 \%$ was found in studies with 5 -fluorouracil-based regimens, $5 \%$ in an earlier study of our group (Küchenmeister et $a l, 2000$ ) and the substitution of an oral prodrug for intravenous 5-fluorouracil does not appear to improve these results, with a pCR rate of $4-9 \%$ (Table 4 ) besides one exception by a group from Korea with a pCR rate of $31 \%$ (Kim et al, 2002). Compared with these data, the addition of irinotecan to 5-fluorouracil in the present study resulted in a gross doubling of the pCR rate to over $20 \%$. These favourable results are in line with those recently reported for the 5-fluorouracil-irinotecan combination by Mehta et al (2003) and Mitchell et al (2001), who achieved a pCR rate of $37 \%$ in 32 patients with T3 tumours, and of $24 \%$ in a patient population which included a few T4 tumours, respectively (Table 4). More recently, pCR rates from 12 to $21 \%$ were reported for the combination of oxaliplatin with 5-fluorouracil or 5-fluorouracil prodrugs.

In the preoperative treatment of other gastrointestinal cancers, like gastric cancer or oesophageal cancer, the rate of PCR is an independent factor for survival (Forastiere et al, 1997; De Vita et al, 2002; Terrosu et al, 2003; Ajani et al, 2004). Also, in our study, the progression-free survival for patients with complete responses or only MRD is higher than for patients with only partial response (4-year OS: $88 \pm 8$ vs $58 \pm 12 \% ; P=0.06$; see Figure 2 ).

Unfortunately, most studies of intensified neoadjuvant chemoradiotherapy did not report long-term results with regard to local control, late toxicities or, most importantly, the probability of distant metastasis. We have therefore evaluated our data after a long median follow-up of 36 months, with a minimum follow-up of 24 months for surviving patients. In randomised trials, well over $30 \%$ of the patients with stage II or III rectal cancer developed distant dissemination. However, neoadjuvant chemoradiation 
Overview of preoperative chemoradiotherapy with different chemotherapeutics

\begin{tabular}{|c|c|c|c|c|c|}
\hline Study & No. of patients & Chemotherapy & RT dose & Diarrhoea III/IV & PCR (\%) \\
\hline \multicolumn{6}{|l|}{ 5-Fluorouracil } \\
\hline Sauer et al, 2004 & 421 & 5-FU & 50.4 & $12 \%$ & 8 \\
\hline \multicolumn{6}{|l|}{ Oral 5-FU prodrugs } \\
\hline Fernandez-Martos et al, 2004 & 94 & UFT & 45 & $14 \%$ & 9 \\
\hline Dunst et al, 2004 & 98 & Capecitabin & $50.4+5.4$ & $4 \%$ & 4 \\
\hline \multicolumn{6}{|l|}{ 5-FU/oxaliplatin } \\
\hline Gerard et al, 2003 & 40 & 5-FU/oxaliplatin & 50 & $17 \%$ & 15 \\
\hline Pinto et al, 2004 & 26 & 5-FU/oxaliplatin & $45+5.4$ & $14 \%$ & 12 \\
\hline \multicolumn{6}{|l|}{ Oral 5-FU prodrugs/oxaliplatin } \\
\hline Rodel et al, 2003 & 32 & Capecitabin/oxaliplatin & 50.4 & $12 \%$ & 19 \\
\hline Glynne-Jones et al, 2004 & 86 & Capecitabin/oxaliplatin & 45 & $10 \%$ & 21 \\
\hline \multicolumn{6}{|l|}{ Oral 5-FU prodrugs/irinotecan } \\
\hline Hofheinz et al, 2004 & 19 & Capecitabin/irinotecan & $45+5.4$ & $16 \%$ & 21 \\
\hline Klautke et al, 2004 & 23 & Capecitabin/irinotecan & $50.4+5.4$ & $39 \%$ & 18 \\
\hline
\end{tabular}

regimens including 5-fluorouracil alone have failed to prevent tumour spread to distant organs. The size of the problem related to distant metastasis in locally advanced rectal cancer becomes even more evident if one considers not only selected study populations but also consecutive patient series in everyday practice. In a retrospective analysis of patients who received adjuvant chemoradiotherapy with 5-fluorouracil and folinic acid at the University of Würzburg, Germany, distant failures occurred in as much as $49 \%$ of stage III patients (Bagatzounis et al, 2000). Although the patients in our phase II study had comparatively large, advanced tumours, only $24 \%$ developed distant metastasis, and among those with R0 resection the rate was as low as $14 \%$. Taking also into account the extended follow-up, these results possibly suggest an improved systemic effect of our intensified neoadjuvant treatment

\section{REFERENCES}

Ajani JA, Mansfield PF, Janjan N, Morris J, Pisters PW, Lynch PM, Feig B, Myerson R, Nivers R, Cohen DS, Gunderson LL (2004) Multiinstitutional trial of preoperative chemoradiotherapy in patients with potentially resectable gastric carcinoma. J Clin Oncol 22: 2774-2780

Bagatzounis A, Willner J, Oppitz U, Flentje M (2000) The postoperative adjuvant radiation therapy and radiochemotherapy for UICC stage II and III rectal cancer. A retrospective analysis. Strahlenther Onkol 176: $112-117$

Boothmann DA, Trask DK, Pardee AB (1987) Inhibition of potential lethal damage repair in human tumor cells by lapachone, an activator of topoisomerase I. Cancer Res 49: 605-612

Boscia RE, Korbut T, Holden SA, Ara G, Teicher BA (1993) Interaction of topoisomerase I inhibitors with radiation in cis-diamminedichloroplatinum (II)-sensitive and -resistant cells in vitro and in the FSAIIC fibrosarcoma in vivo. Int J Cancer 53: 118-123

Chan A, Wong A, Langevin J, Khoo R (1993) Preoperative concurrent 5 -fluorouracil infusion, mitomycin $\mathrm{C}$ and pelvic radiation therapy in tethered and fixed rectal carcinoma. Int J Rad Oncol Biol Phys 25: $791-799$

Chen AY, Choy H, Rothenberg ML (1999) DNA topoisomerase I-targeting drugs as radiation sensitizers. Oncology (Huntingt) 13: 39-46 regimen compared with the other adjuvant or neoadjuvant protocols reported so far. Of course these data has to be proven in phase III trials comparing neoadjuvant 5-fluorouracil-based treatment with intensified schemes with oxaliplatin or irinotecan.

Another interesting, though preliminary, finding of our study was the outstanding prognostic significance of postoperative nodal status. While $\mathrm{pN} 0$ and $\mathrm{pN} 1$ patients had progression-free survivals at 4 years of 92 and $80 \%$, respectively, all pN2 patients had a recurrence, usually at a distant site, within the first 2 years (Figure 1). It is likely therefore that the former group of patients will not benefit from further intensification of treatment. In contrast, additional postoperative therapy, perhaps in the form of maintenance chemotherapy, should be strongly considered in pN2 patients.
De Vita F, Di Martino N, Orditura M, Cosenza A, Galizia G, Del Genio A, Catalano G (2002) Preoperative chemoradiotherapy for aquamous cell carcinoma and adenocarcinoma of the esophagus: a phase II study. Chest 122(4): $1302-1308$

Douillard JY, Cunningham D, Roth AD, Navarro M, James RD, Karasek P, Jandik P, Iveson T, Carmichael J, Alakl M, Gruia G, Awad L, Rougier P (2000) Irinotecan combined with fluorouracil compared with fluorouracil alone as first-line treatment for metastatic colorectal cancer: a multicentre randomised trial. Lancet 355: 1041-1047

Dunst J, Reese T, Debus J, Hoelscher T, Budach W, Rudat V, Wulf J, Mose $S$, Hinke A (2004) Phase-II-Study of preoperative chemoradiation with capecitabine in rectal cancer. Proc Am Soc Clin Oncol 22: 14S (Abstr 3559)

Fernandez-Martos C, Aparicio J, Bosch C, Torregrosa M, Campos JM, Garcera S, Vicent JM, Maestu I, Climent MA, Mengual JL, Tormo A, Hernandez A, Estevan R, Richart JM, Viciano V, Uribe N, Campos J, Puchades R, Arlandis F, Almenar D (2004) Preoperative Uracil, Tegafur, and Concomitant Radiotherapy in Operable Rectal Cancer : A Phase II Multicenter Study With 3 Years' Follow-Up. J Clin Oncol 22: 3016-3022

Forastiere AA, Heitmiller RF, Lee DJ, Zahurak M, Abrams R, Kleinberg L, Watkins S, Yeo CJ, Lillemoe KD, Sitzmann JV, Sharfman W (1997) 
Intensive chemoradiation followed by esophagectomy for squamous cell and adenocarcinoma of the esophagus. Cancer J Sci Am 3(3): 144-152

Fyles AW, Milosevic M, Pintilie M, Syed A, Hill RP (2000) Anemia, hypoxia, and transfusion in patients with cervix cancer: a review. Radiother Oncol 57: $13-19$

Gerard JP, Chapet O, Nemoz C, Romestaing P, Mornex F, Coquard R, Barbet N, Adeleine P, Freyer G (2003) Preoperative concurrent chemoradiotherapy in locally advanced rectal cancer with high-dose radiation and oxaliplatin-containing regimen: the Lyon R0-04 phase II trial. J Clin Oncol 21: 1119-1124

Glynne-Jones R, Sebag-Montefiore D, McDonald A, Falk S, Maughan T (2004) Preliminary phase II SOCRATES study results: Capecitabine (CAP) combined with Oxaliplatin (OX) and preoperative radiation (RT) in patients (pts) locally advanced rectal cancer (LARC). Onkologie 27(suppl 1): 12-58, (Abstr 3575)

Grann A, Minsky BD, Cohen AM, Saltz L, Guillem JG, Paty PB, Kelsen DP, Kemeny N, Ilson D, Bass-Loeb J (1997) Preliminary results of preoperative 5-fluorouracil, low-dose leucovorin, and concurrent radiation therapy for clinically resectable T3 rectal cancer. Dis Colon Rectum 40: $515-522$

Hermanek P, Wittekind C (1994) The pathologist and the residual tumor (R) classification. Pathol Res Pract 190: 115-123

Hofheinz R, von Gerstenberg B, Wenz F, Gnad-Vogt U, Tiefenbacher U, Saussele S, Kreil S, Hochhaus A, Willeke F (2004) Phase I study of irinotecan and capecitabine in combination with concurrent radiotherapy for locally advanced rectal cancer. Proc Am Soc Clin Oncol 22: 14 S (abstr 3696)

Hyams DM, Mamounas EP, Petrelli N, Rockette H, Jones J, Wieand HS, Deutsch M, Wickerham L, Fisher B, Wolmark N (1997) A clinical trial to evaluate the worth of preoperative multimodality therapy in patients with operable carcinoma of the rectum: a progress report of National Surgical Breast and Bowel Project Protocol R-03. Dis Colon Rectum 40: $131-139$

Keilholz L, Dworak O, Dunst J, Kockerling F, Schwarz B, Sauer R (1995) Präoperative Radiochemotherapie bei primär inoperablen Rektumkarzinomen. Strahlenther Onkol 171: 70-76

Kim JS, Kim JS, Cho MJ, Song KS, Yoon WH (2002) Preoperative chemoradiation using oral capecitabine in locally advanced rectal cancer. Int J Radiat Oncol Biol Phys 54(2): 403-408

Klautke G, Foitzik Th, Ludwig K, Klar EJM, Fietkau R (2004) Intensified neoadjuvant chemoradiotherapy with capecitabine and irinotecan in patients with locally advanced rectal cancer: a phase I/II study. Proc Am Soc Clin Oncol 22: 14S (abstr 3693)

Küchenmeister U, Kirchner R, Mellert J, Klautke G, Mucke R, Hopt UT, Fietkau R (2000) Erste Ergebnisse der neoadjuvanten simultanen Radiochemotherapie bei fortgeschrittenen ektumkarzinomen. Strahlenther Onkol 176: $560-566$

Kumar P (2000) Impact of anemia in patients with head and neck cancer. Oncologist 5: 13-18

Maghfoor I, Wilkes J, Kuvshinoff B, Westgate S, Bryer M, Perry MC, Miedema B, Doll D, Ota D (1997) Neoadjuvant chemoradiotherapy with sphincter-sparing surgery for low lying rectal cancer. Proc Am Soc Clin Oncol 16: 274a (abstr 971)

Mehta VK, Cho C, Ford JM, Jambalos C, Poen J, Koong A, Lin A, Bastidas JA, Young H, Dunphy EP, Fisher G (2003) Phase II trial of preoperative
3D conformal radiotherapy, protracted venous infusion 5-fluorouracil, and weekly CPT-11, followed by surgery for ultrasound-staged T3 rectal cancer. Int J Radiat Oncol Biol Phys 55: $132-137$

Minsky BD, Cohen A, Kemeny N, Enker WE, Kelsen DP, Saltz L, Frankel J (1993) The efficacy of preoperative 5-fluorouracil, high-dose leucovorin, and sequential radiation therapy for unresectable rectal cancer. Cancer 71: $3486-3492$

Mitchell EP, Anne P, Fry R, Ahmad N, Boman B, Edmunston T, Rakinic J, Goldstein S, Rose L, Palazzo J, Cagir B, Kovatich A, Hauck W, Fishel R, Bonanni R, Hoey D, Rose D, Curran W, Jefferson T (2001) Combined mortality therapy of locally advanced or recurrent adenocarcinoma of the rectum: report of a phase I Trial of chemotherapy with CPT-11, 5-FU and concomitant irradiation. Proc Am Soc Clin Oncol 20: 131a (abstr 519)

Omura M, Torigoe S, Kubota N (1997) SN-38, a metabolite of the camptothecin derivative CPT-11, potentiates the cytotoxic effect of radiation in human colon adenocarcinoma cells grown as spheroids Radiother Oncol 43: $197-201$

Pinto C, Gentile AL, Iacopino B, Neri S, Ugolini G, Minni F, Ceccarelli C, Martinelli GN, Cola B, Martoni A (2004) Neoadjuvant therapy with oxaliplatin and 5-fluorouracil continuous infusion combined with radiotherapy in rectal cancer: first results of the Bologna phase II study. Onkologie 27(Suppl 1): 12 - 58 (abstr 3557)

Riepl M, Pietsch A, Klautke G, Fehr R, Fietkau R (2000) Endoscopic pretherapeutic clipping for gastrointestinal tumors. A method for exact definition of the target volume. Strahlenther Onkol 176: 517-523

Rodel C, Grabenbauer GG, Papadopoulos T, Hohenberger W, Schmoll HJ, Sauer R (2003) Phase I/II trial of capecitabine, oxaliplatin, and radiation for rectal cancer. J Clin Oncol 21: 3098-3104

Rodel C, Grabenbauer GG, Schick C, Papadopoulos T, Hohenberger W, Sauer R (2000) Präoperative simultane Radiochemotherapie mit 5 Fluorouracil bei lokal fortgeschrittenen T4-Rektumprimärtumoren. Strahlenther Onkol 176: $161-167$

Roh MS, Petrelli N, Wieland S, Colangelo L, Smith R, Mamounas E, Hyams D, Wolmark N (2001) Phase III randomized trial of preoperative versus postoperative multimodality therapy in patients with carcinoma of the rectum (NSABP R-03). Proc Am Soc Clin Oncol 20: 123a (abstr 490)

Saltz LB, Cox JV, Blanke C, Rosen LS, Fehrenbacher L, Moore MJ, Maroun JA, Ackland SP, Locker PK, Pirotta N, Elfering GL, Miller LL (2000) Irinotecan plus fluorouracil and leucovorin for metastatic colorectal cancer. Irinotecan Study Group. N Engl J Med 343: $905-914$

Sauer R, Becker H, Hohenberger W, Rodel C, Wittekind C, Fietkau R, Martus P, Tschmelitsch J, Hager E, Hess CF, Karstens JH, Liersch T, Schmidberger H, Raab R (2004) Preoperative versus postoperative chemoradiotherapy for rectal cancer. $N$ Engl J Med 351: 1731-1740

Seegenschmiedt MH (1998) Interdisciplinary documentation of treatment side effects in oncology. Present status and perspectives Strahlenther Onkol 174: 25-29

Terrosu G, Cedolini C, Bresadola V, Baccarani U, Uzzau A, Signor M, Fongione S, Buffoli A, Iop A, Vigevani E, Sacco C, Cartei G, Bresadola F (2003) Preoperative chemoradiotherapy in cancer of the thoracic esophagus. Dis Esophagus 16(1): 9-16

Videtic G, Fisher B, Perera FE, Bauman GS, Kocha WI, Taylor M, Vincent MD, Plewes EA, Engel CJ, Stitt LW (1998) Preoperative radiation with concurrent 5-fluorouracil continuous infusion for locally advanced unresectable rectal cancer. Int J Rad Oncol Biol Phys 42: 319-324 